\title{
Influence of Annealing and Irradiation by Heavy Ions on Optical Absorption of Doped Lithium Niobate Crystals
}

\author{
P. POTERA* AND I. STEFANiUk \\ Faculty of Mathematics and Natural Sciences, University of Rzeszów, T. Rejtana 16A, 35-310 Rzeszów, Poland \\ (Received January 22, 2016; in final form May 27, 2016) \\ The present work is devoted to investigation of optical absorption changes in Fe and $\mathrm{Cu}$ doped $\mathrm{LiNbO}_{3}(\mathrm{LNO})$ \\ single crystals induced during annealing in vacuum and air as well as under influence of the ${ }^{209} \mathrm{Bi}$ ions irradiation \\ with energy $11.4 \mathrm{MeV} / \mathrm{u}\left(\mathrm{MeV}\right.$ per nucleon) and a fluence $5 \times 10^{11} \mathrm{~cm}^{-2}$ at room temperature. The analysis \\ of changes of absorption of the crystal during air annealing have been studied in the Arrhenius coordinates and \\ activation energies have been determined.
}

DOI: 10.12693/APhysPolA.130.800

PACS/topics: 81.40.Gh, 61.80.-x, 78.20.--e

\section{Introduction}

Unique physical properties of lithium niobate $\mathrm{LiNbO}_{3}$ (LNO) single crystals lead to their wide use in various fields of science and engineering, for example acoustooptics, opto- and quantum electronics. The lithium niobate crystals doped with $\mathrm{Fe}$ or $\mathrm{Cu}$ ions are used as holographic storage media [1].

It is known that annealing of the oxide crystals in different atmospheres can change the optical absorption of the crystals $[2-4]$. Annealing can produce new point defects, for example oxygen vacancies or removing existing defects, and also can lead to the charge change of point defects or dopants $[2,4]$.

Implantation of light ions from energy in the few $\mathrm{MeV}$ range is a standard procedure to produce optical waveguides at visible and near-IR wavelengths in LNO and in many other crystals $[5,6]$, but also heavy mass ions ( $\mathrm{Kr}, \mathrm{Xe}$ ) having energies in the $\approx 10 \mathrm{MeV} / \mathrm{u}$ range have been successfully used to produce thick planar LNO optical waveguides [7]. At the end of their range, ions are implanted and severe structural damage is produced by elastic collisions with the atoms of the target material, leading to the formation of a buried layer having a lower density and refractive index than the virgin crystal [7].

Heavy ion implantation is a versatile tool for fabrication of embedded metal nanoparticles and for modification of domain structures of ferroelectrics [8]. In particular, heavy-ion implantation has an advantage, because the injected elements are immiscible.

The ionizing radiation can also affect the optical properties of the LNO crystals and there are many publications devoted to the investigation of the colour centres $(\mathrm{CC})$ created by various kinds of ionizing radiation (UV light, gamma quanta, electrons, neutrons) on pure LNO crystals or doped by photorefractive ions, for example in [9-13]. However, the CC formation in these

\footnotetext{
${ }^{*}$ corresponding author; e-mail: ppotera@univ.rzeszow.pl
}

crystals under the ion irradiation was studied insufficiently, and was performed practically only for light ions

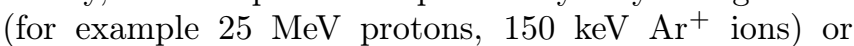
for low-energy heavy ions (for example $23 \mathrm{keV} \mathrm{Au}^{+}$, $60 \mathrm{keV} \mathrm{Cu}^{+}$) [14-17]. The optical absorption of LNO irradiated by swift heavy ions was studied only for $0.8 \mathrm{GeV}$ ${ }^{155} \mathrm{Gd}$ ions [18] and $3 \mathrm{MeV} \mathrm{Cu}$ ions [19].

The present work is devoted to the investigation of the optical changes in vacuum and air annealed or ${ }^{209} \mathrm{Bi}$ irradiated LNO: $\mathrm{Cu}(0.03 \%)$ and LNO:Fe $(0.2 \% \mathrm{~mol})$ crystals.

\section{Experimental details}

The investigated crystals were grown by the Czochralski method in condition described in [9]. For optical measurements the polished plates of the crystals with thickness of $1 \mathrm{~mm}$ were used.

The selected samples were annealed in vacuum in temperature $500^{\circ} \mathrm{C}$ by $1 \mathrm{~h}$. The other "as grown" samples were isochronally annealed (for $30 \mathrm{~min}$ at temperature range $200-800^{\circ} \mathrm{C}$ with step $100^{\circ} \mathrm{C}$ ) using a LHT $04 / 16$ NABERTHERM furnace with C42 controller. The temperature during each heating was stable within $1 \mathrm{~K}$. The transmission spectra of annealed samples were measured at room temperature.

The other samples of crystals were irradiated by ${ }^{209} \mathrm{Bi}$ ions with energy $11.4 \mathrm{MeV} / \mathrm{u}$ (the total particle energy was $2382 \mathrm{MeV}$ ) and fluence $5 \times 10^{11} \mathrm{~cm}^{-2}$ at room temperature in GSI (Darmstadt, Germany). To exclude other influence during irradiation, the samples during irradiation were protected by $\mathrm{Al}$ foil (thickness of $10 \mu \mathrm{m}$ ) which reduces the ion energy to $1787 \mathrm{MeV}$. Penetration depth and finally trapped Bi concentration have not been determined. The samples irradiated with bismuth ions have cracked perpendicular to the surface into few parts and their absorption was measured for the area free from visible destructions for selected part of sample.

The transmission spectra were recorded using spectrophotometer Cary 5000. The induced additional absorption (AA) was calculated as 


$$
\Delta K=K_{2}-K_{1}=\frac{1}{d} \ln \frac{T_{1}}{T_{2}},
$$

where $d$ is the sample thickness, $T_{1}$ and $T_{2}$ are the optical transmission values before and after treatment (annealing or irradiation), respectively.

\section{Results}

The optical absorption spectra of as-grown LNO:Fe and LNO:Cu crystals above $10000 \mathrm{~cm}^{-1}$ are shown in Fig. 1. A broad absorption band with maximum at $21000 \mathrm{~cm}^{-1}$ is observed in Fe-doped crystal that is due to intervalence electron transition $\mathrm{Fe}^{2+} \rightarrow \mathrm{Nb}^{5+}[20]$ as well as a slight increase of absorption below $12500 \mathrm{~cm}^{-1}$ connected with ${ }^{5} T_{2} \rightarrow{ }^{5} E$ electron transition of $\mathrm{Fe}^{2+}$ ions was observed (Fig. 1) [21]. A wide and weak band centred at $25000 \mathrm{~cm}^{-1}$ associated with the intervalent transition $\mathrm{Cu}^{+} \rightarrow \mathrm{Nb}^{5+}[22]$ is present for LNO:Cu crystal (Fig. 1).

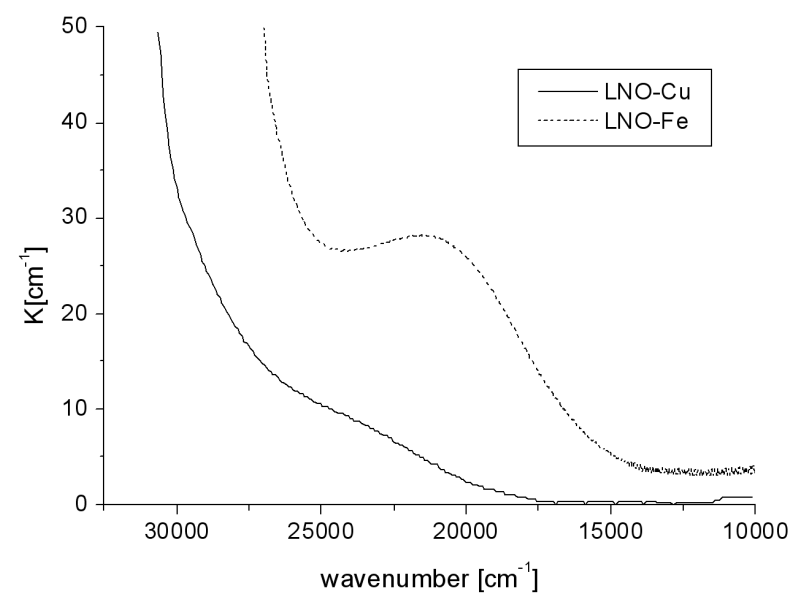

Fig. 1. Absorption spectra of LNO:Cu and LNO:Fe crystal.

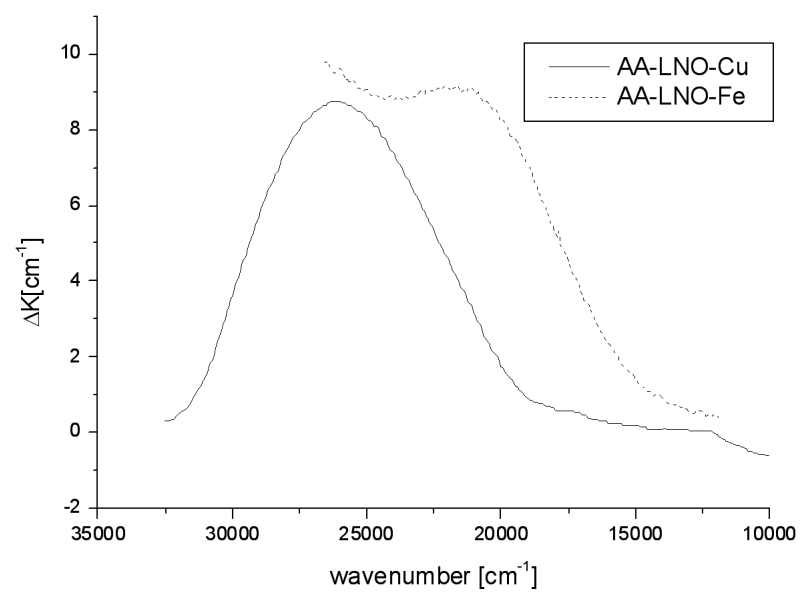

Fig. 2. AA of vacuum annealed LNO:Fe and LNO:Cu crystals.

After vacuum annealing the strong absorption growth for both samples of LNO:Cu and LNO:Fe were observed. The AA of LNO:Cu sample showed a wide intense band with maximum near $25000 \mathrm{~cm}^{-1}$ (Fig. 2). The increase of absorption LNO:Cu crystal with maximum near $25000 \mathrm{~cm}^{-1}$ connected with slight decrease of absorption near $9650 \mathrm{~cm}^{-1}$ have been also observed in work [22] after reducing annealing in argon $\left(500-900^{\circ} \mathrm{C}\right)$ and vacuum $\left(600-700^{\circ} \mathrm{C}\right)$. According to authors of Ref. [22] the absorption changes are associated with charge change of copper ions. In our opinion the absorption change observed by us is due to growth of concentration of $\mathrm{Cu}^{+}$ ions (leading to increase of intensity of the transition $\mathrm{Cu}^{+} \rightarrow \mathrm{Nb}^{5+}$ ) during annealing as a results of reaction $\mathrm{Cu}^{2+}+2 \mathrm{O}^{2-} \rightarrow \mathrm{O}_{2} \uparrow+2 \mathrm{~V}_{\mathrm{O}}+\mathrm{Cu}^{+}+3 \mathrm{e}^{-}$.

In AA spectrum of LNO:Fe sample the maximum in $21000 \mathrm{~cm}^{-1}$ (Fig. 2) connected with increase of intensity of intervalence electron transition $\mathrm{Fe}^{2+} \rightarrow \mathrm{Nb}^{5+}$ is observed. This fact suggests that during vacuum annealing the growth of concentration of $\mathrm{Fe}^{2+}$ ions takes place due to reducing iron ions $\left(\mathrm{Fe}^{3+}+2 \mathrm{O}^{2-} \rightarrow \mathrm{O}_{2} \uparrow+2 \mathrm{~V}_{\mathrm{O}}+\right.$ $\mathrm{Fe}^{2+}+3 \mathrm{e}^{-}$). In final for both LNO samples the produced oxygen vacancies can capture the electrons becoming Ftype centers, which have contribution to the growth of absorption. In works $[10,11]$ the growth of absorption of LNO:Fe with maximum near $23800 \mathrm{~cm}^{-1}$ or $21000 \mathrm{~cm}^{-1}$ were observed as results of $1.6 \mathrm{MeV}$ electron irradiation (with fluency $10^{14} \mathrm{~cm}^{-2}$ ) and X-ray irradiation, consequently. The increase of absorption was connected with growth of concentration of $\mathrm{Fe}^{2+}$ ions by charge change of $\mathrm{Fe}^{3+}$ ions $[10,11]$. The annealing of electron-irradiated LNO:Fe crystal in air leads to the absorption decrease due to hole trapping by $\mathrm{Fe}^{2+}$ ions [10]. The presence of other optical active centers in LNO:Fe is rather very unlikely. In work [23] there was shown that annealing of pure LNO produce growth of crystal absorption below $16500 \mathrm{~cm}^{-1}$ is connected with creation of polarons as results of dissociation of bipolarons. Unfortunately, we did not observe the decrease of absorption band with maximum near $21000 \mathrm{~cm}^{-1}$ connected with bipolaron dissociation.

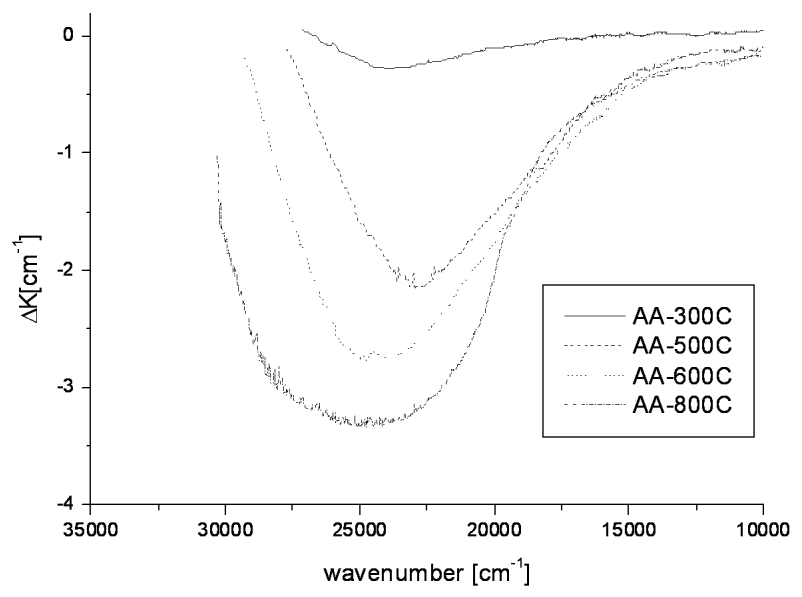

Fig. 3. AA of air annealed LNO:Cu crystal for selected annealing temperatures. 


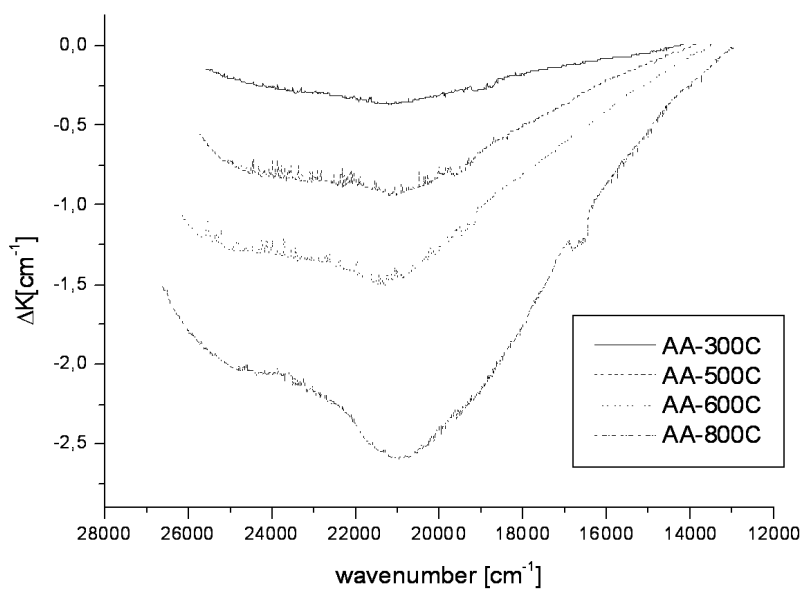

Fig. 4. As in Fig. 3, but for LNO:Fe crystal.

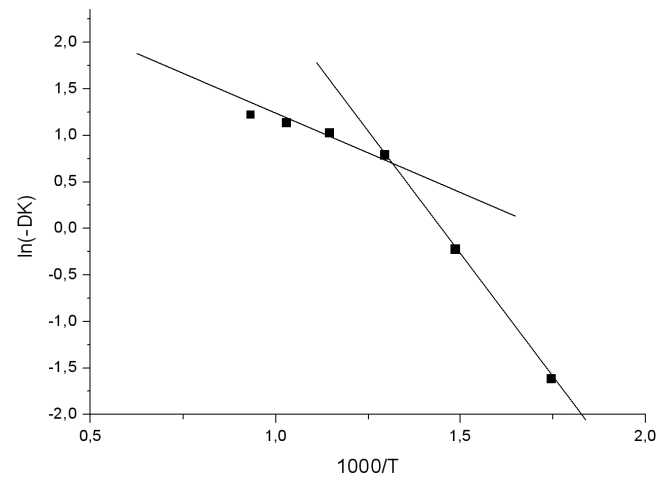

Fig. 5. The AA coefficient in $25000 \mathrm{~cm}^{-1}$ of air annealed LNO: $\mathrm{Cu}$ crystal in Arrhenius coordinates.

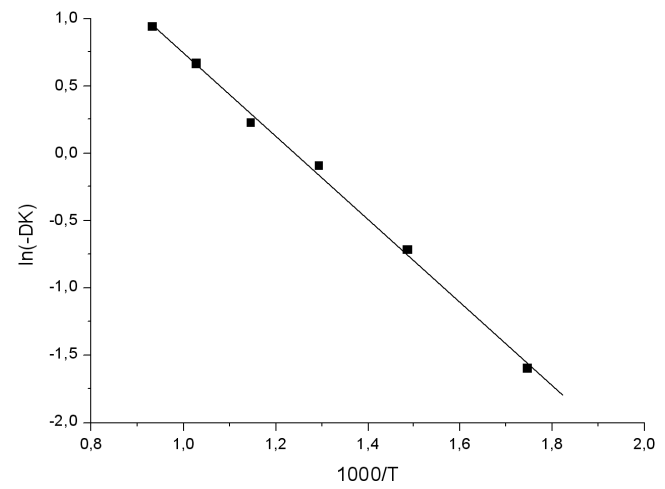

Fig. 6. The absorption coefficient in $21000 \mathrm{~cm}^{-1}$ of air annealed LNO:Fe crystal in Arrhenius coordinates.

The annealing of LNO:Cu and LNO:Fe samples in air leads to decrease of absorption of the samples (Fig. 3,4). The value of AA depends on the temperature of isochronous annealing. The annealing in $200^{\circ} \mathrm{C}$ practically does not influence the sample absorption for both crystals and has not been taken into account. The character of AA for both air annealed crystals suggests that decrease of absorption is mainly connected with charge change of dopants ions $\left(\mathrm{Fe}^{2+} \rightarrow \mathrm{Fe}^{3+}, \mathrm{Cu}^{+} \rightarrow \mathrm{Cu}^{2+}\right)$.
The experimental data analysis in the Arrhenius coordinates (Figs. 5, 6) shows that the absolute value of additional absorption coefficient depending on annealing temperature can be well approximated by one (LNO:Fe) and two $(\mathrm{LNO}: \mathrm{Cu})$ straight lines. The approximation have been performed for $21000 \mathrm{~cm}^{-1}$ (LNO:Fe) and $25000 \mathrm{~cm}^{-1}$ (LNO:Cu) using "linear approximation" in Microcal Origin program. The estimated activation energies as well as their accuracy are given in Table I.

\section{TABLE I}

Activaction energy of the two-step process annealing in air.

\begin{tabular}{c|c|c}
\hline \hline Sample & $E_{a}[\mathrm{eV}]$ & $\begin{array}{c}\text { Coefficient of } \\
\text { determination }\left(R^{2}\right)\end{array}$ \\
\hline LNO:Cu & 0.11 & 0.999 \\
& 0.46 & 0.975 \\
LNO:Fe & 0.27 & 0.997
\end{tabular}

For LNO:Cu the defect has been annealed in two-stage process. We suggest that besides of dopant $(\mathrm{Cu})$ the electron F-type centers (single or double charged anion vacancy) are responsible for near band absorption in LNO: $\mathrm{Cu}$ crystals. In the annealing process the charge change of $\mathrm{Cu}$ ions takes place and oxygen will fill the oxygen vacancy and after electron-hole recombination the regular lattice is restored. For LNO:Fe the one-step process takes place connected with charge change of Fe ions.

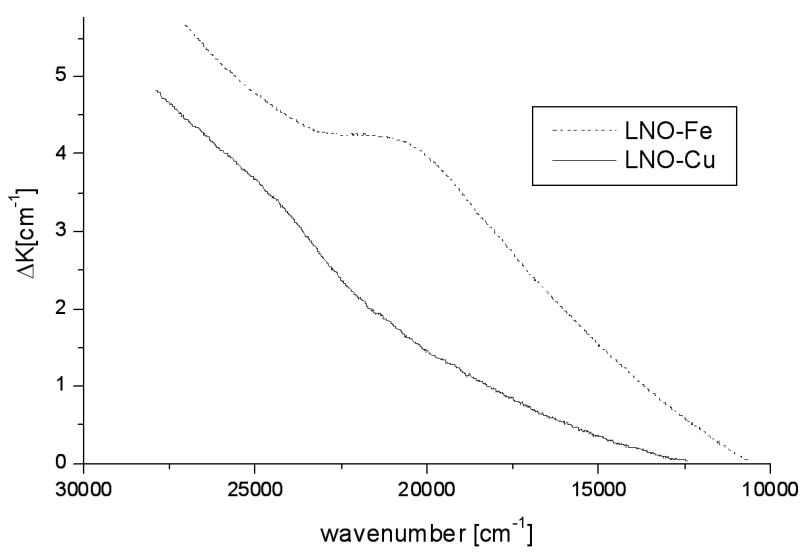

Fig. 7. The AA bismuth ion irradiated LNO:Cu and LNO:Fe crystals.

The irradiation by ${ }^{209} \mathrm{Bi}$ ions with an energy $2382 \mathrm{MeV}$ and a fluence of $5 \times 10^{11} \mathrm{~cm}^{-2}$ lead to the change of optical absorption in tested LNO:Fe and LNO:Cu crystals (Fig. 7).

The additional absorption (Fig. 7) showed wide spectrum without clear structure. For LNO:Fe slight maximum near $21000 \mathrm{~cm}^{-1}$ is observed, which may be associated with $\mathrm{Fe}^{2+}$ iron ions.

In contrast to the irradiation by protons [15], the authors of the paper [18] also observed that irradiation of LNO crystal by $5.17 \mathrm{MeV} / \mathrm{u}^{155} \mathrm{Gd}$ ions at room 
temperature with fluence extended from $1.5 \times 10^{11}$ to $1.2 \times 10^{12}$ ions $\mathrm{cm}^{-2}$ produce unstructured additional absorption.

The nature of defects responsible for induced absorption after Bi ions irradiation is not entirely clear. During irradiation a different kind of defects can be produced as track defects, aggregates of defects, complex defects or single point defects as well as change charge of dopant ions can take place.

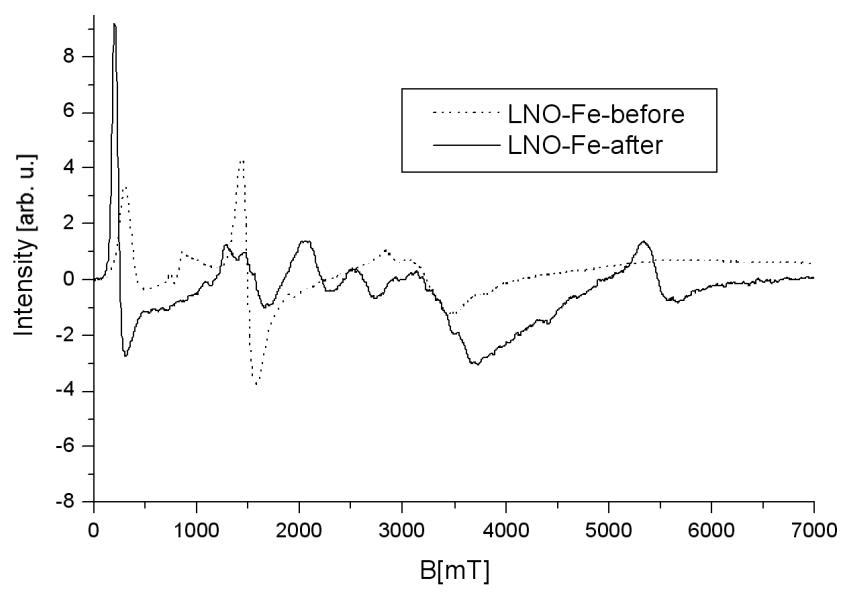

Fig. 8. The EPR spectra of LNO:Fe crystal before and after irradiation.

The part of these centers have paramagnetic nature and manifest in the EPR spectrum of the LNO:Fe crystal in the form of numerous lines (Fig. 8). The complicated structure of the EPR spectra, from comparison with unirradiated sample (Fig. 8) indicates presence of various paramagnetic centers.

It was shown that at very high electronic stopping powers (a few tens of $\mathrm{keV} / \mathrm{nm}$ ), resulting from $\mathrm{GeV}$ heavy ion irradiations, significant damage may occur in materials insensitive to ionization processes [24] as induced point and extended defects in monocrystalline phase [25]. In work [26] there has been hypothesized that in the $5 \mathrm{MeV}$ oxygen-implanted lithium niobate the nuclear damage provides the localization of the energy released to the electronic subsystem necessary for the conversion into atomic displacements. Additionally, it was shown in [27] that ion irradiation can lead to the amorphization of surface $\mathrm{ABO}_{3}$ type crystals. All these processes can take place in our samples.

The lattice damage can be also induced by elastic nuclear collisions and implantation [28, 29]. For example, damage induced defects by ion irradiations in lithium niobate were observed for swift ( $\mathrm{GeV}$ range) ${ }^{112} \mathrm{Sn},{ }^{155} \mathrm{Gd}$, and ${ }^{238} \mathrm{U}$ ions with fluences extending not below $10^{10} \mathrm{~cm}^{-2}$ for the high electronic stopping power $(\mathrm{d} E / \mathrm{d} x)_{e}$, between 18 and $40 \mathrm{keV} \mathrm{nm}^{-1}[30]$. In this case damage cross-section $\sigma_{d}$ varies from $4 \times 10^{-13}$ to $1.4 \times 10^{-12} \mathrm{~cm}^{2}[30]$. Each of these processes (electronic interactions, nuclear collisions) can result in the creation of optically active centers in Bi irradiated LNO crystals.

\section{Conclusion}

The annealing of LNO:Fe and LNO:Cu in vacuum leads to the growth of absorption of the crystals due to change of charge of dopants. After air annealing the opposite effects were observed. Irradiation by high energy bismuth ions leads to the growth of the absorption of the crystals due to production of different defects.

\section{Acknowledgments}

This work is supported by grant of the Dean of the Faculty of Mathematics and Natural Science of University of Rzeszów no. WMP/GD-29/2015. I would like to thank Prof. Kurt Schwartz for sample irradiation.

\section{References}

[1] K. Buse, F. Jerman, E. Kratzing, Opt. Mater. 4, 237 (1995).

[2] D. Millers, H.M. Yochum, V. Pankratov, P. Potera, L. Grigorjeva, Phys. Status Solidi C 4, 1155 (2007).

[3] A. Garcia-Cabanes, E. Dieguez, J.M. Cabrera, F. Agullo-Lopez, J. Phys. Condens. Matter 1, 6453 (1989).

[4] S.M. Kaczmarek, M. Berkowski, Z. Moroz, S. Warchoł, Acta Phys. Pol. A 96, 417 (1999).

[5] F. Chen, X.-L. Wang, K.-M. Wang, Opt. Mater. 29, 1523 (2007).

[6] F. Chen, J. Appl. Phys. 106, 081101 (2009).

[7] J. Olivares, M.L. Crespillo, O. Caballero-Calero, M.D. Ynsa, A. García-Cabañes, M. Toulemonde, Ch. Trautmann, F. Agulló-López, Opt. Express 17, 24175 (2009).

[8] Y. Takeda, N. Umeda, V.T. Gritsyna, N. Kishimoto, Nucl. Instrum. Meth. Phys. Res. B 175-177, 463 (2001).

[9] I. Pracka, A.L. Bajor, S.M. Kaczmarek, M. Swirkowicz, B. Kaczmarek, J. Kisielewski, T. Łukasiewicz, Cryst. Res. Technol. 34, 627 (1999).

[10] E.R. Hodgson, F. Agullo-Lopez, J. Phys. Condens. Matter 3, 285 (1991).

[11] T.R. Volk, N.M. Rubinina, Phys. Status Solidi A 108, 437 (1988).

[12] A.O. Matkovskii, P. Potera, D.Yu. Sugak, Ya. Zhydachevskii, V. Pankratov, D. Millers, L. Grigorjeva, I. Pracka, T. Lukasiewicz, Cryst. Res. Technol. 38, 388 (2003).

[13] S.B. Ubizskii, A.O. Matkovskii, N. Mironova-Ulmane, V. Skvortsova, A. Suchocki, Y.A. Zhydachevskii, P. Potera, Phys. Status Solidi A 177, 349 (2000).

[14] I.W. Kim, B.Ch. Park, B.M. Jin, J.H. Jeong, K.S. Lee, Ferroelectrics 269, 243 (2002).

[15] S.M. Kaczmarek, R. Jablonski, I. Pracka, M. Swirkowicz, J. Wojtkowska, S. Warchol, Cryst. Res. Technol. 34, 729 (1999).

[16] D.Y. Shang, H. Matsuno, Y. Saito, S. Suganomata, J. Appl. Phys. 80, 406 (1996). 
[17] O.A. Plaksin, K. Kono, Y. Takeda, S.O. Plaksin, V.Ya. Shur, N. Kishimoto, Ferroelectrics 373, 127 (2008).

[18] B. Canut, R. Brenier, A. Meftah, P. Moretti, S. Ould Salem, S.M.M. Ramos, P. Thevenard, M. Toulemonde, Nucl. Instrum. Methods Phys. Res. B 91, 312 (1994).

[19] K. Ijima, N. Mitsui, A. Ho, J. Yamanaka, S. Taniguchi, Y. Saito, Nucl. Instrum. Methods Phys. Res. B 257, 472 (2007).

[20] M.G. Clark, F.J. Di Salvo, A.M. Glass, G.E. Peterson, J. Chem. Phys. 59, 6209 (1973).

[21] O.F. Schirmer, O. Thiemman, M. Wochlecke, J. Phys. Chem. Solids 52, 185 (1991).

[22] L. Arizmendi, J.M. Cabrera, F. Agullo-Lopez, J. Phys. C Solid State Phys. 17, 515 (1984).

[23] O.F. Schirmer, M. Imlau, C. Merschajann, B. Schoke, J. Phys. Condens. Matter 21, 123201 (2009).

[24] M. Toulemonde, C. Dufour, E. Paumier, Phys. Rev. B 46, 14362 (1992).
[25] B. Canut, S.M.M. Ramos, P. Thevenard, N. Moncoffre, A. Benyagoub, G. Marest, A. Meftah, M. Toulemonde, F. Studer, Nucl. Instrum. Methods Phys. Res. B 80/81, 1114 (1993).

[26] M. Bianconi, N. Argiolas, M. Bazzan, G.G. Bentini, M. Chiarini, A. Cerutti, P. Mazzoldi, G. Pennestrì, C. Sada, Appl. Phys. Lett. 87, 072901 (2005).

[27] A. Meldrum, L.A. Boatner, W.J. Weber, R.C. Ewing, J. Nucl. Mater. 300, 242 (2002).

[28] A. Rivera, J. Olivares, G. García, F. Agulló-López, Nucl. Instrum. Methods Phys. Res. B 266, 2859 (2008).

[29] A. Rivera, J. Olivares, G. García, J.M. Cabrera F. Agulló-Rueda, F. Agulló-López Phys. Status Solidi A 206, 1109 (2009).

[30] B. Canut, S.M.M. Ramos, R. Brenier, P. Thevenard, J.L. Loubet, M. Toulemonde, Nucl. Instrum. Methods Phys. Res. B 107, 194 (1996). 